\title{
Production of biodegradable sodium caseinate film containing titanium oxide nanoparticles and grape seed essence and investigation of physicochemical properties
}

\author{
Roghiye Ashrafi Yorghanlu \\ West Azerbaijan University of Technology \\ Haleh Hemmati \\ West Azerbaijan University of Technology \\ Sajad Pirsa ( $\triangle$ pirsa7@gmail.com ) \\ Urmia University https://orcid.org/0000-0002-6182-8798 \\ Arezu Makhani \\ West Azerbaijan University of Technology
}

\section{Research Article}

Keywords: Biodegradable, Biopolymer, Antioxidant, Active, Nanocomposite

Posted Date: June 17th, 2021

DOI: https://doi.org/10.21203/rs.3.rs-627498/v1

License: (c) (i) This work is licensed under a Creative Commons Attribution 4.0 International License.

Read Full License 


\section{Abstract}

In this study sodium caseinate film was produced and the effect of titanium oxide nanoparticles and grape seed essence as factors that enhances film properties was investigated. For this purpose, nanocomposite films based on sodium caseinate were modified with different levels of nanoparticles of 0 to $1.5 \%$ and grape seed essence at levels of 0 to $500 \mathrm{ppm}$ based on the central composite experimental design (CCD). The effects of these variables on physical/mechanical properties, water vapor permeability and antioxidant properties were investigated. The morphology and chemical structure of different films were evaluated by SEM and FTIR techniques. The results showed that the addition of titanium oxide nanoparticles has improved the mechanical properties of the films. In this regard, films prepared from $1.5 \%$ and $500 \mathrm{ppm}$ nanoparticles have the highest tensile strength. The results of scanning electron microscopy test showed that the addition of nanoparticles led to the indirect penetration of water, which reduced the permeability of the films to water vapor to $4.89 \mathrm{~kg} / \mathrm{m}$. The addition of grape seed essence caused the antioxidant effects of the produced films, so that the films containing $250 \mathrm{ppm}$ showed antioxidant activity of $86.74 \%$. Overall, the results showed that the addition of nanoparticles and grape seed essence had positive effects on the physical and chemical properties of sodium caseinate.

\section{Introduction}

Today, food packaging is an important part of the global food industry, which is important in the world due to increasing consumer demand for safe food, the shelf life of packaged food, and reducing costs. In recent decades, with the introduction of new technologies such as active, intelligent packaging and even nanotechnology into the field of food packaging, new and clear horizons have been created in this industry. Conventional food packaging systems passively protect food by creating a barrier between the food and its surroundings, while active food packaging is defined as a system that is not only able to act as a barrier, but also by establishing a favorable relationship with the food protect the food. For example active packaging by releasing the antimicrobial and antioxidant compounds in the food protects food. The effects of this relationship usually cause food stability [1-6]. Oxidation of fats after the growth of microbes is the most important cause of food spoilage. Fatty foods and foods containing unsaturated fatty acids are the most susceptible to spoilage. Fat oxidation causes unpleasant odors and spoilage of food and makes them inedible. In some cases, toxic aldehydes are formed and the breakdown of unsaturated fatty acids destroys the nutritional properties [7-9]. One of the most notable developments under the active packaging subset is the edible and degradable films. In the food industry, these packages can control or prevent the reactions that occur inside the packages. Biocompatible packaging based on food films has special importance due to its natural materials, and renewability [10 and 11]. Casein proteins are fibrous proteins with a random spiral structure and are present in milk in the form of micelles. Casein micelles are composed of components of casein, calcium phosphate, citrate and magnesium. The use of biopolymer films is associated with limitations due to problems with their performance, the inherent sensitivity to water and relatively low resistance, especially in humid environments. Sodium caseinate is no exception to this general feature, and its hydrophilicity and poor 
mechanical properties in humid environments and insufficient heat resistance and hardness have made its application in the packaging industry difficult [12]. Nanotechnology, and in particular nanomaterials, has provided promising solutions to address some of the barriers to the application of biopolymers for the packaging of food and beverages. Improved capabilities and new packaging concepts are made possible by advances in nanomaterial production technologies. Nanometer-sized titanium dioxide is an ideal photocatalyst, the most important reason for this property is its ability to absorb ultraviolet rays. Titanium dioxide nanoparticles are known as a source of white pigment for polymers due to their very high stability and relatively uniform absorption of visible light, and are used to improve the color of packaging materials [13 and 14]. According to Zhou et al. (2009), the addition of titanium dioxide nanoparticles in whey protein films can greatly improve the physical and mechanical properties of films and increase their inhibition of water vapor [15]. To prolong the shelf life of food, synthetic antioxidants are mainly added to them in industrial processing. The findings of nutritionists have shown that the harmful side effects of these antioxidants have been recorded in food processing such as butylated hydroxytoluene (BHT) and butylated hydroxyanisole (BHA). Today, in order to eliminate or reduce chemical and synthetic compounds in food, much research has been done to replace chemicals with natural compounds. Phenolic compounds and polyphenols are among the most important phytochemical compounds that are considered as one of the sources of natural antioxidants due to the hydroxyl group in their chemical structure. Essential oils and extracts of medicinal plants with antimicrobial, anticancer, antioxidant and free radical scavenging capacity have a very high potential to be used as new natural preservatives in the protection of raw foods [16].

Grape seed essential oil has a very mild flavor, which is mainly composed of triglycerides that contain more than $90-80 \%$ of unsaturated fatty acids. This oil contains $14-15 \%$ oleic acid, $61-73 \%$ linoleic acid, $0.6 \%$ alpha-linolenic acid and about $10-18 \%$ palmitic acid and stearic acid. The essential oil of the kernel contains $0.8-1.5 \%$ of non-saponifiable substances, which often consists of sterols and tocopherols and has antioxidant properties and also contains proanthocyanidins, which are a group of bioflavonoid antioxidants. Grape seed essential oil, like other vegetable oils such as palm and coconut, contains natural sources of tocopherols and has a much higher antioxidant power, so despite its high saturation, it is oxidative stable due to its above stabilizing compounds [17]. During the studies on the effect of grape seed extract on bread, it was reported that the bread containing grape seed extract had a stronger antioxidant power than the control sample, and increasing the level of grape seed extract strengthened its antioxidant properties. As the amount of extract increases, the antioxidant power will also increase [18].

In another study, the effect of adding grape seed extract $(1 \% \mathrm{w} / \mathrm{w})$ on the physical and microbial properties of soy protein isolate film was investigated and the results showed that the participation of grape seed extract in the composition of edible film increased thickness, perforation, tissue strength and stability compared to control samples, and due to the presence of grape seed extract, Listeria monocytogenes activity was prevented and the shelf life and safety of instant food products stored in these films were improved [19]. 


\section{Materials And Methods}

For film production, raw materials include sodium caseinate (99\% purity) (Milad Khorasan Dairy Powder Company), titanium oxide (98\% purity) (Sigma-America), grape seed essence (Horticulture Department of Urmia University), glycerol, tween 80 (Merck, Germany) and 2-2-diphenyl - 1- Picrylhydrazyl (DPPH) (Sigma-America) were prepared. Other chemical compounds used in this study were prepared by Merck and Aldridge companies and used without re-purification.

\subsection{Film production}

To prepare the film, $4 \mathrm{~g}$ of sodium caseinate powder was dissolved in $50 \mathrm{ml}$ of distilled water and stirred for 2 hours at $56^{\circ} \mathrm{C}$ at $1200 \mathrm{rpm}$. Also, the titanium oxide solution was prepared (according to the Table 1) in $50 \mathrm{ml}$ of distilled water at $25^{\circ} \mathrm{C}$ and stirred at $1200 \mathrm{rpm}$. To produce the film, $50 \mathrm{ml}$ of sodium caseinate solution was added to the titanium oxide solution and stirred for one hour. Glycerol ( $50 \%$ by weight of sodium caseinate) and $2 \mathrm{ml}$ tween 80 were added to the above solution and stirred for half an hour. Grape seed essence was added to the mixture (according to the Table 1) and stirred at $1200 \mathrm{rpm}$ for 2 minutes. The final solution was poured onto a plate $(10 \times 10 \mathrm{~cm})$ and dried at $25^{\circ} \mathrm{C}$ for 48 hours. The films were stored in a desiccator at $25^{\circ} \mathrm{C}$ to prepare for analysis (Fig. 1). 
Table 1

List of experiments based on CCD

\begin{tabular}{|c|c|c|}
\hline Run & $\mathrm{A}: \mathrm{TiO}_{2}(\%)$ & B: Essence (ppm) \\
\hline 1 & 0.75 & 0 \\
\hline 2 & 0 & 250 \\
\hline 3 & 1.5 & 250 \\
\hline 4 & 0.75 & 0 \\
\hline 5 & 0 & 250 \\
\hline 6 & 1.5 & 0 \\
\hline 7 & 0.75 & 250 \\
\hline 8 & 0 & 500 \\
\hline 9 & 1.5 & 500 \\
\hline 10 & 0.75 & 500 \\
\hline 11 & 1.5 & 0 \\
\hline 12 & 0.75 & 250 \\
\hline 13 & 0.75 & 250 \\
\hline 14 & 0 & 500 \\
\hline 15 & 0.75 & 250 \\
\hline 16 & 0.75 & 250 \\
\hline 17 & 0 & 0 \\
\hline 18 & 0 & 0 \\
\hline 19 & 1.5 & 250 \\
\hline 20 & 1.5 & 500 \\
\hline 21 & 0.75 & 500 \\
\hline
\end{tabular}

\subsection{Film tests}

\subsubsection{Thickness measurement}

To determine the thickness of the films, a micrometer (model-25A-3109) with an accuracy of $0.01 \mathrm{~mm}$ was used. Measurements were made at five different points in the film and then averaged. The calculated average thickness was used to determine the tensile strength and water vapor permeability [20]. 


\subsubsection{Moisture content measurement}

To measure the moisture content, the film samples $(0.2 \mathrm{~g})$ were first conditioned in a desiccator containing magnesium nitrate for 48 hours and weighted $(\mathrm{m} 1)$. Then each sample was dried in an oven at $105^{\circ} \mathrm{C}$ and weighed after six hours $(\mathrm{m} 2)$. The moisture content was determined in three replications. The moisture content was calculated according to the following equation.

$$
\text { Moisture }=\frac{m_{1}-m_{2}}{m_{1}} \times 100
$$

\subsubsection{Measurement of solubility in water}

To measure solubility, pieces of film were weighed at $105^{\circ} \mathrm{C}$ for 6 hours and then weighed $\left(W_{1}\right)$. In the next step, the film was immersed in $50 \mathrm{ml}$ of distilled water for 6 hours at $25^{\circ} \mathrm{C}$ and stirred at $250 \mathrm{rpm}$. The solution was then passed through Whatman 4 filter paper and completely dried in the oven and weighed again $\left(\mathrm{W}_{2}\right)$. The solubility was calculated by the following equation [21]:

$$
\text { Solubility }=\frac{\left(\mathrm{W}_{1}-\mathrm{W}_{2}\right)}{W_{1}} \times 100
$$

\subsubsection{Water vapor permeability (WVP)}

Water vapor permeability was measured according to the ASTM E96-92 method used in the study of Casariego o et al. (2009) [22]. For this purpose, special falcons with a diameter of $2 \mathrm{~cm}$ were used. $10 \mathrm{ml}$ of distilled water was poured into the falcons. A piece of film was placed on the Falcon lid and the lid of the vial was closed. The falcons were then weighed and placed in a desiccator containing $24 \%$ salt. Falcon weights were measured every 2 hours for 10 hours. The amount of water vapor transferred from the films was determined by reducing the weight of the falcon. The Falcon weight loss curve was plotted over time and after calculating linear regression, the slope of the resulting line was calculated. By dividing the slope of the weight loss line of each vial to the surface of the film that was exposed to water vapor, the water vapor transfer rate (WVTR) and water vapor permeability (WVP) were calculated according to Equations 3 and 4. In Eq. 1, WVTR is the water vapor transfer rate $\left(\mathrm{Kg} / \mathrm{m}^{2} \mathrm{~s}\right), \mathrm{L}$ is the film thickness $(\mathrm{m})$, $\Delta P$ is the relative water vapor pressure differences in $\mathrm{Pa}$ between the two sides of the film and $\mathrm{A}$ is the film surface $\left(\mathrm{m}^{2}\right)$.

$$
\text { WVTR }=\frac{\text { slope }}{\text { A }}
$$

$$
\text { WVP }=
$$

$\underline{(\mathrm{WVTR} \times \mathrm{L})}$

\subsubsection{Determination of antioxidant properties}


Siripatrawan et al. (2010) method was used to determine the antioxidant capacity of films through DPPH free radical scavenging power [23]. The absorbance was recorded by a spectroscopy instrument (model UV-2100 spectrophotometer) at $517 \mathrm{~nm}$. The antioxidant capacity of the films was calculated as the percentage of DPPH inhibition using Eq. 5 . In this regard, Abs ${ }_{D P P H}$ indicates the absorption of the control sample and $\mathrm{Abs}_{\text {film extract }}$ indicates the absorption of the sample containing film.

\section{DPPH scavenging activity $=\frac{\left(A b s_{D P P H}-A b s \text { film extract }\right)}{A b s D P P H} \times 100$}

\subsubsection{Measurement of mechanical properties of films}

Mechanical tests were measured using a texture analyzer instrument (TA.XT Plus, Stable Micro Systems UK) according to [ASTM-D882-91] standard [20]. Before performing the analysis, the samples were conditioned in a desiccator containing magnesium nitrate at $25^{\circ} \mathrm{C}$ and $89.52 \%$ moisture for 24 hours. Then, a sample of each film was cut in the form of dumbbells with dimensions of $8 \times 0.5 \mathrm{~cm}$ and placed between the two jaws of the device. The initial distance between the two jaws and the speed of movement of the upper jaw were determined to be 30 and $0.833 \mathrm{~mm}$, respectively, and the data were recorded by a computer. Measurement factors include tensile strength (TS) and percentage of strain to break point (STB) and the elongation of the films was measured and reported by the device.

\subsubsection{Opacity}

Visible light blocking properties in films were measured using the method of Jan et al. (2011) using a UV spectrophotometer (211 UV-2100, USA) at the specified wavelength. For this purpose, the film was cut in $1 \times 4 \mathrm{~cm}$ dimension and their thickness was measured at five points along the film and then the film piece was placed in a transparent wall inside the quartz cell of the device and the sample absorption rate was recorded. The opacity of films was calculated by the following equation [24].

$$
\text { opacity }=\frac{-A 600}{\mathrm{X}}
$$

Where, A600 is the absorption rate at a wavelength of $600 \mathrm{~nm}$ and $\mathrm{x}$ is the average film thickness in millimeters.

\subsubsection{Measure the surface color of films}

To measure the surface color, a colorimeter (Colorimeter Minolta model CR-410 Japan) was used. First, the device was calibrated by a standard white screen. The films were then placed on a white plate and their color was measured using a colorimeter. This device measures four wavelengths in the range of visible area waves. The results include three color dimensions with quantitative indices $L^{*}, a^{*}$ and $b^{*}$, which represent lightness (from $L=0$ for black to $L=100$ for white), green to red ( $a=-60$ for green up to a $=+60$ for red) and blue to yellow ( $b=-60$ for blue to $b=+60$ for yellow). Using the following equations, the values of total color difference $(\Delta \mathrm{E})$, whiteness coefficient $(\mathrm{WI})$ and chroma $\left(\mathrm{C}^{\star}\right)$, which show the amount of gray color and imperfections of the film, were calculated. 


$$
\begin{aligned}
& \Delta \boldsymbol{E}=\sqrt{\left(\Delta \mathbf{L}^{*}\right)^{2}+\left(\Delta \mathbf{a}^{*}\right)^{2}+\left(\Delta \mathbf{b}^{*}\right)^{2}} \\
& W I=100-\sqrt{\left(100-L^{*}\right) 2+a^{*} 2+b^{*} 2} \\
& \text { Chroma }=\sqrt{\left(a^{*}\right)^{2}+\left(b^{*}\right)^{2}}
\end{aligned}
$$

\subsubsection{Scanning electron microscopy (SEM)}

The microstructure of the produced films was examined by scanning electron microscope (Tescan Vegan3). In order to investigate the effect of titanium oxide nanoparticles on the microstructures of the produced film, electron microscope images were prepared from the surface of the films. Imaging of the samples was performed by scanning electron microscope with a use of $20 \mathrm{~kW}$ and at a magnification of one micrometer.

\subsubsection{Infrared spectroscopy (FTIR)}

For IR spectroscopy, thin tablets with a thickness of less than one millimeter were obtained by mixing and milling the film sample with dried potassium bromide in a ratio of 1:20 and applying a pressure of about $60 \mathrm{KPa}$ for ten minutes in the tablet preparation machine. The FTIR spectra were analyzed in the range of 500 to $4000 \mathrm{~cm}^{-1}$ with a resolution of $0.5 \mathrm{~cm}^{-1}$.

\subsection{Statistical analysis}

In this study, to investigate the effect of titanium oxide ( 0 to $1.5 \%$ ) and grape seed essence ( 0 to 500 $\mathrm{ppm}$ ) on the physicochemical properties of the film, the central composite design (CCD) (Table 1) was used and appropriate statistical models were analyzed. Design Expert-10 software was used to investigate the linear effect and interaction of variables. Significant levels of data were considered at the level of $5 \%$ probability $(p<0.05)$.

\section{Results And Discussion}

In this study, the response surface method (RSM) and statistical modeling of the relationship between independent variables (titanium oxide percentage and essence concentration) and dependent variables (physicochemical properties of sodium caseinate film) were used to investigate the effect of titanium oxide percentage and essence concentration on physicochemical properties of sodium caseinate film. Table 2 shows the mathematical models of the relationship between the physicochemical properties of the film and the independent variables as well as the regression coefficients and the adjusted regression coefficients. 


\begin{tabular}{|c|c|c|}
\hline Response & Regression equation & $\begin{array}{l}\text { Model } \\
\text { Summary }\end{array}$ \\
\hline$a^{*}$ & $\begin{array}{l}=-5.16+0.74 * \mathrm{TiO} 2+0.001 * \text { Essence- } 0.0006 * \mathrm{TiO}^{\star}{ }^{*} \text { Essence } \\
-0.275^{\star} \mathrm{TiO}^{\wedge} 2-2.15 \mathrm{E}-06 * \text { Essence }^{\wedge} 2\end{array}$ & $\begin{array}{l}\text { R-sq = } \\
0.72 \\
\text { R-sq(adj) } \\
=0.70\end{array}$ \\
\hline$b^{*}$ & $\begin{array}{l}=+11.90+1.316 * \mathrm{TiO} 2+0.001 * \text { Essence }+0.0002 * \mathrm{TiO}^{*}{ }^{*} \text { Essence } \\
-0.710 * \mathrm{TiO}^{\wedge} 2-3.27 \mathrm{E}-06 *{ }^{*} \text { Essence } 2\end{array}$ & $\begin{array}{l}\text { R-sq = } \\
0.84 \\
\text { R-sq(adj) } \\
=0.82\end{array}$ \\
\hline Chroma & $\begin{array}{l}=+12.98+0.94 * \mathrm{TiO} 2+0.001 * \text { Essence }+0.0004 * \mathrm{TiO} 2 * \text { Essence } \\
-0.56 * \mathrm{TiO}^{\wedge} 2-2.19 \mathrm{E}-06 * \text { Essence } 2\end{array}$ & $\begin{array}{l}\text { R-sq = } \\
0.84 \\
\text { R-sq(adj) } \\
=0.79\end{array}$ \\
\hline Whiteness & $\begin{aligned}=+85.56-4.47^{\star}{ }^{\mathrm{TiO} 2} 2-0.01 * \text { Essence }+0.002 * \mathrm{TiO}^{\star}{ }^{*} \text { Essence }+ \\
1.55^{\star} \mathrm{TiO} 2^{\wedge} 2+1.78 \mathrm{E}-05^{\star} \text { Essence }^{\wedge} 2\end{aligned}$ & $\begin{array}{l}\text { R-sq = } \\
0.68 \\
\text { R-sq(adj) } \\
=0.65\end{array}$ \\
\hline$\Delta \mathrm{E}$ & $\begin{array}{l}=+14.91+0.413^{\star} \mathrm{TiO} 2+1.87 \mathrm{E}-05^{\star} \text { Essence }+0.001 * \mathrm{TiO} 2 * \text { Essence } \\
-0.364 * \mathrm{TiO}^{\wedge} 2-2.26 \mathrm{E}-06{ }^{*} \text { Essence }^{\wedge} 2\end{array}$ & $\begin{array}{l}\text { R-sq = } \\
0.89 \\
\text { R-sq(adj) } \\
=0.84\end{array}$ \\
\hline
\end{tabular}

\subsection{Thickness and solubility}

Figure 2 shows the 3D curve of the effect of $\mathrm{TiO}_{2}$ and essence on the thickness and solubility of sodium caseinate based film. Thickness is one of the important factors of films that directly affects the permeability properties to water vapor and oxygen as well as the mechanical properties. According to Fig. 2 and Table 2, the linear effect of titanium oxide and the essence and the quadratic effect of titanium oxide on film thickness was significant $(p<0.05)$. The obtained films were small in thickness and easily separated from the surface of the plates. The lowest thickness is for pure sodium caseinate film. The value of the regression coefficient $\left(R^{2}=0.96\right)$ obtained for the film thickness showed the high efficiency of the model in predicting the film thickness. The maximum thickness is in the film containing $1.5 \%$ of titanium oxide and $500 \mathrm{ppm}$, which is equal to $0.24 \mathrm{~mm}$. It seems that the increase in thickness is due to the increase in dry matter of the films. Also, the absorption of water in the film surface by the hydrogen bonds causes less moisture removing from the films and increases thickness. Intramolecular interaction between the protein chains of sodium caseinate, $\mathrm{TiO}_{2}$ and essence was probably the reason for the 
increase in film density and film thickness. Increasing of film thickness due to the addition of an antioxidant active agent has also been reported by other researchers [25 and 26].

Solubility in water can be one of the most important properties for biodegradable films due to its water resistance, especially in humid environments. In fact, the solubility of films in water determines the release of antioxidant and antimicrobial compounds from active films when used to package food. Water resistance is one of the important features of biodegradable films because it indicates their effectiveness in protecting foods with high water activity or fresh and frozen materials. Due to the hydrophilicity of proteins, the resulting films show high water absorption and solubility, which limits their use alone as coatings and films. Gums and glycerol usually increase solubility due to their solubility in water and lipids decrease solubility due to insolubility. However, sometimes gum and glycerol may reduce solubility due to interactions between film components. The linear and quadratic effects of titanium oxide as well as the linear effect of essence alone on the solubility of the film were significant (Table 2). Also, the effect of titanium oxide on solubility was greater than the effect of the essence. Solubility increased slowly with increasing the amount of essence to a concentration of $500 \mathrm{ppm}$. However, the amount of titanium oxide up to $1.5 \%$ caused a significant reduction in the solubility up to $21.1 \%$. However, at values above these levels, its effect on solubility decreased and the solubility decreased with a slower slope with increasing titanium oxide content. The results of this study are consistent with the results reported by Bourny et al. (2017). Addition of nano-clay through hydrogen and covalent bonds to the protein lattice reduces the free hydrogen groups available to form hydrophilic bonds with the water and ultimately reduces the water activity and moisture content of the protein films. Due to the above fact, in the study of the effect of glycerol on the water solubility of films, it was found that a glycerol changes protein molecular structure by reducing cross-links between polymer chains and significantly increases the solubility of films in water [27].

\subsection{Moisture content and water vapor permeability}

Water resistance is an important feature of biodegradable and edible films because it indicates their effectiveness in protecting foods with high water activity or fresh and frozen materials. Figure 3 shows the 3D curve of the effect of TiO2 and essence on the moisture and WVP of sodium caseinate based film. According to Fig. 2 and Table 2, the amount of moisture was only significantly affected by titanium oxide and the amount of essence had no significant effect on this response. As can be seen in Fig. 3, with increasing the amount of titanium oxide to $1.5 \%$, the moisture content of the film decreased sharply to $4.2 \%$. The high moisture content was $15.8 \%$, which was observed in pure sodium caseinate film. Addition of titanium oxide nanoparticles through hydrogen and covalent bonds to the protein lattice reduces the free hydrogen groups available to form hydrophilic bonds with water and ultimately reduces the water activity and moisture content of protein films [28]. Pirsa et al. (2018) in a study on starch and nano-clay composite films stated that nano-clay reduced the moisture and water solubility of films [29].

One of the main causes of spoilage is relative humidity, so inhibition of water vapor is one of the most important features used for food packaging. According to Fig. 3 , the significance of the model in the WVP 
response indicated the ability of the model to predict the behavior of WVP by varying the amount of titanium oxide and essence (Table 2). On the other hand, the linear effects of titanium oxide, essence and the quadratic effect of the essence on WVP were significant. As shown in Fig. 3, WVP decreased with a steep slope with increasing the amount of titanium oxide to $1.5 \%$ and the essence to $500 \mathrm{ppm}$. The highest amount of WVP is related to pure sodium caseinate film. Regression coefficient of 0.83 meant the high power of the model in predicting WVP. Casein films are completely soluble in water and have a very high inhibitory effect on oxygen, but their water vapor permeability is higher. In general, due to the high number of hydrophilic groups in the polymer chains of carbohydrate and protein films, they have little inhibition against water vapor. Improving the permeability properties of sodium caseinate film is due to the indirect passage of water vapor by titanium nanoparticles scattered in the protein lattice. Pirsa et al. (2018) in a study on cellulose nanofiber films reported that the moisture absorption and water vapor permeability of $\mathrm{BC}$ increased with the addition of $\mathrm{KMnO}_{4}$ [30].

\subsection{Antioxidant activity}

DPPH radical is a stable free radical with a central nitrogen atom that in the presence of antioxidants, DPPH color is changed from purple to yellow by reducing and producing a stable molecule. Figure 4 shows 3D curve and contour plot of the effect of $\mathrm{TiO}_{2}$ and essence on antioxidant activity of films. According to the data obtained from Fig. 4 and Table 2, the predicted model for antioxidant activity was quite significant $(p<0.05)$. Also, the linear effect of the essence and titanium oxide and the quadratic effect of the essence on the antioxidant activity were significant. So that by increasing the amount of titanium oxide to $1.5 \%$, the amount of antioxidant activity is equal to $74.8 \%$. Due to the significant effect of the essence, with increasing the amount of essence to $250 \mathrm{ppm}$, the antioxidant capacity increased sharply, but from a concentration of $250 \mathrm{ppm}$ onwards, the effect of the essence on this response was insignificant $(p>0.05)$. The lowest amount of antioxidant properties is related to the pure sodium caseinate film, which is equal to $3.8 \%$. The high value of the regression coefficient $\left(R^{2}\right)$ of 0.99 also showed higher efficiency and accuracy of the model in predicting the behavior of antioxidant activity. The results of other studies indicate an increase in antioxidant power by adding essence and plant extracts to the film protein matrix [31]. Regarding the antioxidant effect of the essence and grape seed extract, Nasir Muslim et al. (2019) by examining the combined effect of grape seed extract, nettle essential oil and lycopene on the quality of Frankfurter sausage reported that the highest antioxidant property against oxidative spoilage (peroxide number) was observed in treatment containing lycopene $5 \%$, nettle essential oil $2 \%$, and grape seed extract $2 \%$, which contained the highest amount of grape seed extract [32].

\subsection{Mechanical properties}

Figure 5 shows 3D curve of the effect of $\mathrm{TiO}_{2}$ and essence on STB and TS of film. As shown in Fig. 5, as the amount of titanium oxide increased, the STB decreased to $6.9 \%$. The highest amount STB is related to pure sodium caseinate film, which is equal to $52.3 \%$. However, in lower amounts of titanium oxide, the amount of STB decreased with increasing the amount of essence up to $500 \mathrm{ppm}$. The value of the regression coefficient of 0.97 obtained for the amount of STB showed the efficiency of the model in predicting the behavior of this response with respect to the independent variables (essence and titanium 
oxide). The effect of the essence on tensile strength (TS) was insignificant, but the linear and the quadratic effect of titanium oxide on this dependent variable was significant. As shown in Fig. 5, with increasing the amount of titanium oxide to $1.5 \%$, the amount of tensile strength increased. Increased film hardness indicates the effect of nanoparticle reinforcement on the mechanical properties of biodegradable films. The increase in tensile strength may be due to the inherent strength and stiffness of titanium oxide chains, uniform distribution of nano fillers in the protein matrix substrate and high compatibility between nanoparticles and protein lattice due to high surface area. Reduction of tensile strength in higher levels of titanium oxide could be due to the possible accumulation of titanium oxide nanoparticles and the non-uniform distribution of nanoparticles in the protein substrate. The decrease in tensile strength (TS) due to the increase of titanium oxide nanoparticles from a certain amount may be due to the change in the type of nanocomposite structure and non-uniform distribution of nanoparticles in the polymer substrate. In general, the presence of essential oils and extracts disturbs the structural density and reduces the resistance of films containing essential oils to tensile forces and elongation. According to research by various researchers, the addition of antimicrobial compounds to different polymers due to changes in the molecular level, changes the mechanical properties of the films. These changes often reduce the tensile strength of the films due to the destruction of the film matrix. Asadi and Pirsa (2020) have investigated the effect of titanium dioxide nanoparticles on the mechanical properties of polylactic acid films, the results of which confirm the results of the present study [33].

\subsection{Transparency and color properties}

Transparency and light transmission are a very important feature of films that are used as a coating or packaging for food. Light radiation is one of the most important causes of food spoilage. Some products are so sensitive to light that their color, odor and taste are drastically changed with minimal oxidation due to the effects of light. The main challenge for such products is to protect the contents of the package from light. Transparency is also an effective and efficient indicator in determining the particle size information scattered in the polymer matrix, so that particles and granules larger than the visible wavelength block the passage of light and increase the opacity of the films. It should be noted that the usefulness of opaque or transparent film depends on its application in different foods. For example, for high-fat foods, opaque films are more suitable due to high-fat foods high sensitivity to oxidation. In general, transparency and opacity are inversely related. Therefore, high values of transparency indicate low opacity. Transparency of packaging materials is an advantage in food packaging because it affects the attractiveness of the buyer. On the other hand, packaging materials should protect food products from the damaging effects of light, especially UV rays.

Figure 6 shows 3D curve of the effect of $\mathrm{TiO}_{2}$ and essence on transparency and color properties of film. According to Fig. 6 and Table 2, the linear and quadratic effects of titanium oxide and essence on light transmission and transparency were significant $(p<0.05)$. However, the effect of titanium oxide on this response was greater than the effect of the amount of essence. As can be seen in Fig. 6 , the transparency of the film in the minimum amount of nanoparticles and essence is 298. However, with increasing the amount of titanium oxide up to $1.5 \%$ and essence up to $500 \mathrm{ppm}$, the amount of transparency decreases 
from 362.7 to 20.9. The highest transparency was 362 , which is related to the pure sodium caseinate film. The opaque appearance of composite films indicates that the content of titanium oxide nanoparticles blocks the passage of light through the film network, thereby reducing the transparency of composite films containing titanium oxide nanoparticles. The results of this study were consistent with the results of Sothornvit et al. (2009). They reported that the transparency of whey protein isolate films was decreased due to the addition of titanium oxide nanoparticles [34].

Fabra et al. (2009) reported that the optical properties of edible films depend on the internal structure of the network formed during film drying, the mix ability of the phases, the color of the added segments, the type of dispersion, and the size of the dispersed particles [35]. The transparency of the films is affected by the thickness of the films. The results of the present study showed that the pure sodium caseinate film with the lowest thickness has a higher transparency and less turbidity than other samples.

By adding nanoparticles to the pure sample, the thickness of the films increased and the transparency and light transmission of the samples decreased. With the addition of essence to the film composition, the thickness of the produced films was higher than the pure sample of sodium caseinate film and the samples without essence, which increased the opacity and reduced the light transmission of the films. Glycerol used in film preparation also reduces turbidity and increases light transmission in films. Due to its small size, glycerol enters the space between polymer chains and weakens the forces between chains and increases the space between chains. Therefore, the amount of light absorption by the polymer is reduced.

The color and transparency of the packaging film are one of the most important and influential factors in terms of consumer acceptance. Most food packaging films are clear and colorless. However, in some cases, due to the sensitivity of the food product to light and the loss of its nutrients due to optical oxidation, the use of light-blocking and color-forming compounds in packaging films seems essential. The most important color index is the total color difference $(\Delta \mathrm{E}) . \Delta \mathrm{E}$ indicates the amount of color difference between the sample and the standard screen and is a measure of the transparency of the films. The lower the calculated $\Delta \mathrm{E}$ for a sample, the higher the transparency of the film. Other descriptive factors include whiteness, redness, and yellowness [34].

Regarding the lightness $\left(L^{*}\right)$ factor, by examining the mathematical model (Table 2$)$ and Fig. 6 , the significance of the lightness model shows the high power of the model in predicting the lightness response. The linear effect of titanium oxide and the quadratic effect of the essence on the amount of lightness were significant. So that with increasing the amount of titanium oxide to $1.5 \%$ of the amount of essence up to $500 \mathrm{ppm}$, the lightness intensity decreased from 91.1 to 89.5 .

Regarding the $a^{*}$ factor, by examining the mathematical model (Table 2) and Fig. 6 , the effect of the essence and the interaction of the essence and titanium oxide on the amount of $a^{*}$ was significant. As shown in Fig. 6, increasing the amount of titanium oxide to the level of $1.5 \%$ and the essence of $500 \mathrm{ppm}$ increased the value of $a^{\star}$ with a steep slope. The value of $a^{\star}$ for pure sodium caseinate film was equal to -3.5. Regarding the $b^{*}$ factor, by examining the mathematical model (Table 2 ) and Fig. 6 , the fitted model 
was significant for the value of $b^{*}$. The linear and quadratic effects of titanium oxide and the quadratic effect of essence on $b^{*}$ were significant. Due to the significant quadratic effect and the linear effect of titanium oxide on intensity $b^{*}$, the intensity of $b^{*}$ increased with increasing the amount of titanium oxide. However, at levels higher than $0.75 \%$ of titanium oxide, the intensity of b decreased so that in $1.5 \%$ of titanium oxide it decreased from 12.6 to 12.3. Regarding the chroma factor, by examining the mathematical model (Table 2) and Fig. 6 , the linear and quadratic effects of titanium oxide and essence on chroma intensity were evaluated as significant. As shown in Fig. 6, with increasing the amount of titanium oxide to 0.75 , the amount of chroma increased with a steep slope. On the other hand, as the amount of essence, increased to $500 \mathrm{ppm}$, the amount of chroma increased. The regression coefficient of 0.84 for the proposed model also showed the high power and accuracy of the model in predicting the amount of chroma in different levels of essence and titanium oxide. Regarding the whiteness index, by examining the mathematical model (Table 2) and Fig. 6, the linear effect of titanium oxide and the quadratic effect of the essence on the whiteness index were significant. As can be seen in Fig. 6 , with increasing the amount of titanium oxide up to $1.5 \%$ and essence up to $500 \mathrm{ppm}$, the whiteness of the prepared film decreased significantly. Regarding the $\Delta \mathrm{E}$, by examining the mathematical model (Table 2) and Fig. 6 , the linear effects of titanium oxide and essence on the amount of $\Delta E$ were not significant, but the effect of the interaction of the essence and titanium oxide and the quadratic effect of titanium oxide on this response was significant. Due to the significant effect of the secondary degree of titanium oxide, the amount of $\Delta \mathrm{E}$ increased with increasing titanium oxide levels up to $1.5 \%$.

\subsection{SEM and FTIR}

Figure 7 shows the SEM images and FTIR spectra of pure sodium caseinate films and their composite films. As can be seen in the SEM images, the surface of the control film (pure sodium caseinate) is almost smooth, with cracks, and there are bumps in parts of the film that are most likely due to the presence of protein granules. By examining films containing essence and titanium oxide, the proper density of the film containing essence is due to the strong connections between the hydrophilic protein compounds and the essence when the films are dried. By adding titanium oxide nanoparticles to the protein network, the surface cracks of the composite are reduced. The reduction of cracks in the surface of films containing nanoparticles is probably due to the proper density of titanium oxide and the complete dissolution of the nanoparticles in the protein film matrix. With the increase of titanium oxide nanoparticles, the crack state of the lattice disappears and more non-uniformity is observed than the control film. Song et al. (2013) reported that the addition of clay nanoparticles to protein films causes nanocomposite films containing clay nanoparticles to have more non-uniformity than the control film due to the presence of nanoparticles in interconnected polymer network [36]. Pirsa et al. (2018) in reviewing the films produced from cellulose nanofibers also pointed out the conclusion that zinc oxide and polypyrrole nanoparticles are located between cellulose fiber particles and have caused more uniformity of the films [37].

Examination of FTIR spectra showed that the peaks in the range of $3200 \mathrm{~cm}^{-1}$ to $3600 \mathrm{~cm}^{-1}$ are related to the vibrations of the $\mathrm{O}-\mathrm{H}$ groups (alcohols and phenols). The peaks observed in 690 to 900 are related 
to the vibrations of the $\mathrm{CH}$ groups (aromatic rings), and the peak in 1680 is related to the absorption of water by sodium caseinate. In the pure sodium caseinate film spectrum, the peaks in the range of 400 $\mathrm{cm}^{-1}$ to $1000 \mathrm{~cm}^{-1}$ are related to the bonds that form the amide group ( $\mathrm{C}-\mathrm{O}, \mathrm{N}-\mathrm{H}$, and $\mathrm{C}-\mathrm{N}$ ). The peak in the range of $3200 \mathrm{~cm}^{-1}$ to $3600 \mathrm{~cm}^{-1}$ is related to the tensile vibrations of the $\mathrm{O}-\mathrm{H}$ groups. By adding titanium oxide to the protein film, changes in the structure of the spectra were observed. The intensity and width of the peaks increased in the range of $400 \mathrm{~cm}^{-1}$ to $1500 \mathrm{~cm}^{-1}$ with the addition of nano-titanium, which indicates an increase in hydrogen bonds between sodium caseinate and titanium oxide. In general, the FTIR spectra of the composite film showed the effect of titanium oxide and essence on the position, width and intensity of peaks related to the interactions of the composite film components. These changes in peaks by Pereda et al. (2011) are also evident in the FTIR spectra of sodium caseinate composite films containing cellulose nanocrystals [38].

The general conclusion is that the spectrum of composite films is similar to the spectrum of pure sodium caseinate film and differs only in a few parts. These changes are probably due to the reaction between the $\mathrm{O}-\mathrm{H}$ groups present in the sodium carboxylate caseinate groups with the titanium oxide and essence groups. It can also be said that the position of vibration peaks belonging to different functional groups (such as $\mathrm{OH}, \mathrm{CH}, \mathrm{CC}, \mathrm{C}=\mathrm{C}$, etc.) In pure sodium caseinate films have shifted to different wave numbers in composite films, which indicates the creation of electrostatic interactions between sodium caseinate, titanium oxide and essence.

\section{Conclusion}

The use of titanium oxide improves the overall performance of sodium caseinate film and is a factor in expanding its use as a biodegradable package. Considering the results obtained from this study, the combination of small amounts of titanium oxide in the matrix of the sodium caseinate network caused a significant improvement in the physical and mechanical properties of the film. Appropriate interaction between protein matrix and titanium oxide was expressed as the main factor reducing WVP and water sensitivity and improving the mechanical properties of sodium caseinate films. With the increase of titanium oxide, the transparency of the films decreased, and according to the results of the SEM test, the surface of the composite films became non-uniform. Evaluation of compatibility of grape seed oil with sodium caseinate in order to produce an active composite film had satisfactory results and the composition of the essence with sodium caseinate gave good antioxidant power to the films.

\section{Declarations}

\section{Conflict of interest}

There is not any Conflict of interest between authors.

The authors whose names are listed in the manuscript certify that they have NO affiliations with or involvement in any organization or entity with any financial interest (such as honoraria; educational 
grants; participation in speakers' bureaus; membership, employment, consultancies, stock ownership, or other equity interest; and expert testimony or patent-licensing arrangements), or non-financial interest (such as personal or professional relationships, affiliations, knowledge or beliefs) in the subject matter or materials discussed in this manuscript.

\section{References}

[1] Casariego, A., Souza, B., Cerqueira.m M., Texeira, J., Cruz, Diaz, R., and Vicente, A. 2009. Chitosan0clay films properties as affected by biopolymer and clay micro/nanoparticales concentration. Food Hydrocolloids. 23, 1895- 1902.

[2] Pirsa, S., Mohtarami, F. and Kalantari, S., 2020. Preparation of biodegradable composite starch/tragacanth gum/nanoclay film and study of its physicochemical and mechanical properties. Chemical Review and Letters, 3(3), pp.98-103.

[3] Mohammadi, B., Pirsa, S. and Alizadeh, M., 2019. Preparing chitosan-polyaniline nanocomposite film and examining its mechanical, electrical, and antimicrobial properties. Polymers and Polymer Composites, 27(8), pp.507-517.

[4] Pirsa, S., Farshchi, E. and Roufegarinejad, L., 2020. Antioxidant/antimicrobial film based on carboxymethyl cellulose/gelatin/TiO 2-Ag nano-composite. Journal of Polymers and the Environment, 28(12), pp.3154-3163.

[5] Pirsa, S., 2020. Biodegradable film based on pectin/Nano-clay/methylene blue: Structural and physical properties and sensing ability for measurement of vitamin C. International Journal of Biological Macromolecules, 163, pp.666-675.

[6] Pirsa, S. and Aghbolagh Sharifi, K., 2020. A review of the applications of bioproteins in the preparation of biodegradable films and polymers. Journal of Chemistry Letters, 1(2), pp.47-58.

[7] Chavoshizadeh, S., Pirsa, S. and Mohtarami, F., 2020. Sesame oil oxidation control by active and smart packaging system using wheat gluten/chlorophyll film to increase shelf life and detecting expiration date. European Journal of Lipid Science and Technology, 122(3), p.1900385.

[8] Asdagh, A. and Pirsa, S., 2020. Bacterial and oxidative control of local butter with smart/active film based on pectin/nanoclay/Carum copticum essential oils/ $\beta$-carotene. International Journal of Biological Macromolecules, 165, pp.156-168.

[9] Pirsa, S. and Asadi, S., 2021. Innovative smart and biodegradable packaging for margarine based on a nano composite polylactic acid/lycopene film. Food Additives \& Contaminants: Part A, pp.1-14.

[10] Sivarooban, N., Hettiarachchy, S., and Johnson, M. G. 2006. Physical and antimicrobial properties of grape seed extract, nisin, and EDTA incorporated soy protein edible films. Food Research International. 41, 
[11] Asdagh, A., Sani, I.K., Pirsa, S., Amiri, S., Shariatifar, N., Eghbaljoo-Gharehgheshlaghi, H., Shabahang, Z. and Taniyan, A., 2021. Production and characterization of nanocomposite film based on whey protein isolated/copper oxide nanoparticles containing coconut essential oil and paprika extract. Journal of Polymers and the Environment, 29(1), pp.335-349.

[12] Pires, C., Ramos, C., Teixerira, B., and Batista, M. 2013. Hake protein edible films incorporated with essential oils: physical, mechanical, antioxidant and antimicrobial properties. Food Hydrocolloid, 30. 224231.

[13] Kowalczyk, D., and Baranika, B. 2011. Effect of plasticizers, pH and heating of film-forming solution on the properties of pea protein isolates films. Journal of Food Engineering, 105: 2. 295-305.

[14] Ghasemi, S., Bari, M.R., Pirsa, S. and Amiri, S., 2020. Use of bacterial cellulose film modified by polypyrrole/TiO2-Ag nanocomposite for detecting and measuring the growth of pathogenic bacteria. Carbohydrate polymers, 232, p.115801.

[15] Zhou, A., Wang, S.Y., and Gunasekaran, S. 2009. Preparation and Characterization of Whey Protein Film Incorporated with TiO2 Nanoparticles. Journal of Nano scale Food Science, Engineering, and Technology. 74: 7. 50-56.

[16] Perron, N. R., and Brumaghim, J. L. 2009. A review of the antioxidant mechanisms of polyphone compounds related to iron binding. Cell Biochem Biophys, 53. 75-100.

[17] Luque-Rodrígueza. J.M, Luque de Castroa. M.D, P.Pérez-Juanb. 2005. Extraction of fatty acids from grape seed by superheated hexane. Talanta, 68:1. 126-130.

[18] Peng, X., Jinyu, Ma., Cheng, Ka. W., Jiang, Y., Chen, F., and Wang M. 2010. The effects of grape seed extract fortification on the antioxidant activity and quality attributes of bread .Food Chemistry, 119. 49 -53 .

[19] Sivarooban, N., Hettiarachchy, S., and Johnson, M. G. 2006. Physical and antimicrobial properties of grape seed extract, nisin, and EDTA incorporated soy protein edible films. Food Research International. 41, 761-765.

[20] Sharifi, K.A. and Pirsa, S., 2021. Biodegradable film of black mulberry pulp pectin/chlorophyll of black mulberry leaf encapsulated with carboxymethylcellulose/silica nanoparticles: Investigation of physicochemical and antimicrobial properties. Materials Chemistry and Physics, 267, p.124580.

[21] Hosseini, S.N., Pirsa, S. and Farzi, J., 2021. Biodegradable nano composite film based on modified starch-albumin/MgO; antibacterial, antioxidant and structural properties. Polymer Testing, 97, p.107182. 
[22] Casariego, A., Souza, B., Cerqueira.m M., Texeira, J., Cruz, Diaz, R., and Vicente, A. 2009. Chitosan0clay films properties as affected by biopolymer and clay micro/nanoparticales concentration. Food Hydrocolloids. 23, 1895- 1902.

[23] Siripatrawan. U., and Harte. B. R. 2010. Physical properties and antioxidant activity of an active film from chitosan incorporated with green tea extract. Food Hydrocolloids. 24. 770-775.

[24] Han, J.H., 2014. Edible films and coatings: a review. Innovations in food packaging, pp.213-255.

[25] Penge, Y., Wu, Y., and Li, Y.(2013). Development of tea extracts and chitosan composite Films For active packaging materials. International gournal of biological macromolecules 59,282-289.

[26] Lim, G., Jang, S., and Song. K. B. 2010. Physical and antimicrobial properties of elidium corneum/nano-clay composite film containing grapefruit seed extract or . thymol. Food Engineering Journal. 98. 415-420.

[27] Bourny, V., Perez-Puyana, V., Felix, M., Romero, A. and Guerrero, A., 2017. Evaluation of the injection moulding conditions in soy/nanoclay based composites. European Polymer Journal, 95, pp.539-546.

[28] Song, N.B., Jo, W.S., Song, H.Y., Chung, K.S., Won, M., Song, K.B. 2013. Effect of plasticizers and nano-clay content on physical properties of chicken feather protein composite films. Food Hydrocolloid., 31. 340-345.

[29] Pirsa, S., Karimi Sani, I. and Khodayvandi, S., 2018. Design and fabrication of starch-nano clay composite films loaded with methyl orange and bromocresol green for determination of spoilage in milk package. Polymers for Advanced Technologies, 29(11), pp.2750-2758.

[30] Pirsa, S. and Chavoshizadeh, S., 2018. Design of an optical sensor for ethylene based on nanofiber bacterial cellulose film and its application for determination of banana storage time. Polymers for Advanced Technologies, 29(5), pp.1385-1393.

[31] Sani, I.K., Geshlaghi, S.P., Pirsa, S. and Asdagh, A., 2021. Composite film based on potato starch/apple peel pectin/ZrO2 nanoparticles/microencapsulated Zataria multiflora essential oil; investigation of physicochemical properties and use in quail meat packaging. Food Hydrocolloids, 117, p.106719.

[32] Nasir Muslim, N., Ariayi, P., and Ahmadi, M. 2019. The combined effect of grape seed extract, nettle essential oil and lycopene on the quality of Frankfurter sausage, Journal of Innovation in Food Science and Technology, 10(4), 1-11.

[33] Asadi, S. and Pirsa, S., 2020. Production of biodegradable film based on polylactic acid, modified with lycopene pigment and TiO 2 and studying its physicochemical properties. Journal of Polymers and the Environment, 28(2), pp.433-444. 
[34] Sothornvit, R., Rhim, j., Hong, s., (2009). Effect of nano-clay type on the physical and antimicrobial properties of whey protein isolate/clay composite films, Journal of Food Engineering 91 : 468-473.

[35] Fabra M.J., Talens P., Chiralt A. (2009). Microstructure and optical properties of sodium caseinate films containing oleic acid-beeswax mixtures, Food Hydrocoll. 23 (3), 676-683.

[36] Song, N.B., Jo, W.S., Song, H.Y., Chung, K.S., Won, M., Song, K.B. 2013. Effect of plasticizers and nano-clay content on physical properties of chicken feather protein composite films. Food Hydrocolloid., 31. 340-345.

[37] Pirsa, S., Shamusi, T. and Kia, E.M., 2018. Smart films based on bacterial cellulose nanofibers modified by conductive polypyrrole and zinc oxide nanoparticles. Journal of Applied Polymer Science, 135(34), p.46617.

[38] Pereda, M., Amica, G., Rácz, I. and Marcovich, N.E., 2011. Structure and properties of nanocomposite films based on sodium caseinate and nanocellulose fibers. Journal of Food Engineering, 103(1), pp.7683.

\section{Figures}


a
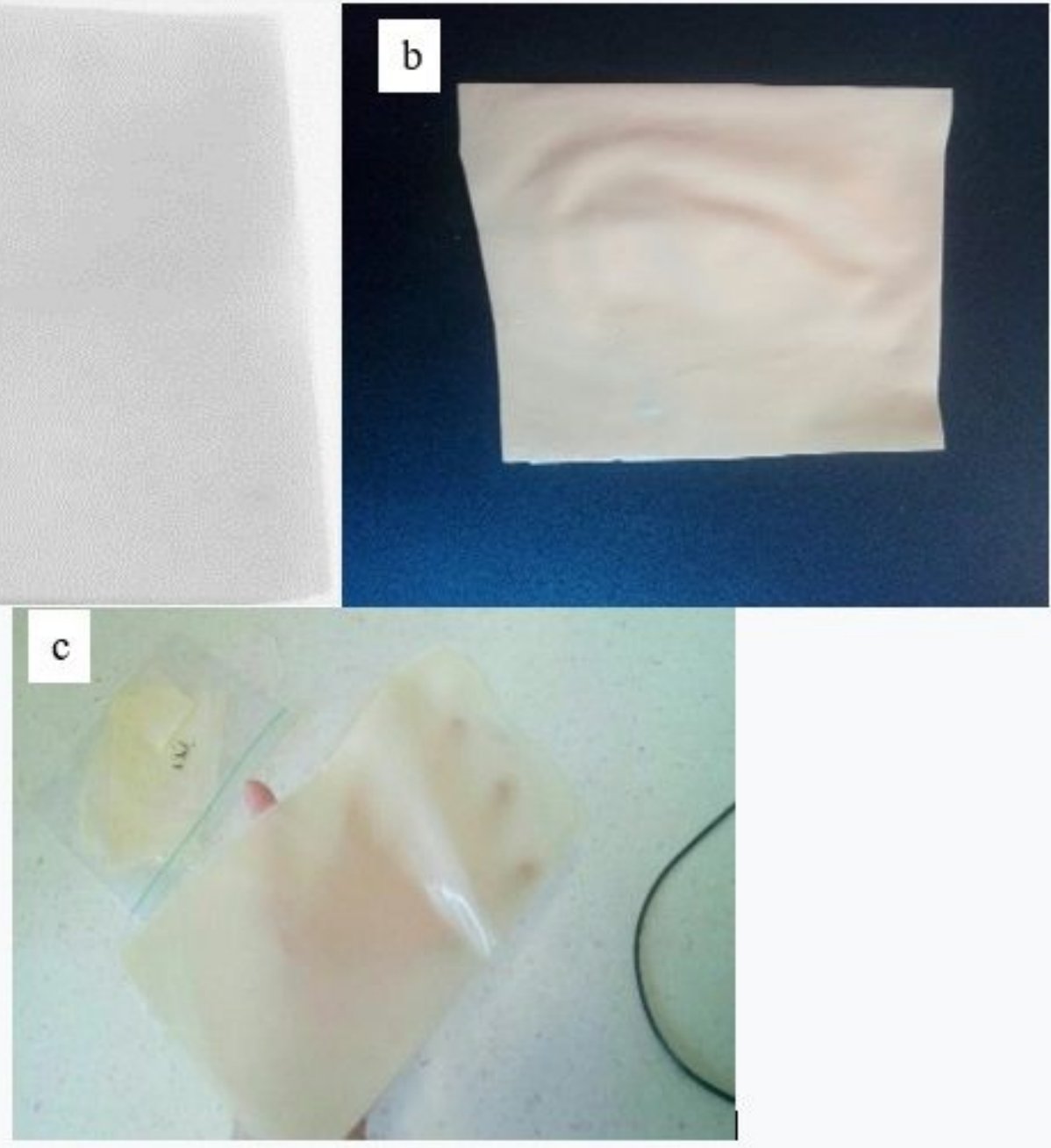

Figure 1

Pure sodium caseinate film (a), sodium caseinate/TiO2 0.75\%/essence 250 ppm (b) and sodium caseinate/TiO2 1.5\%/essence 500 ppm (c) 

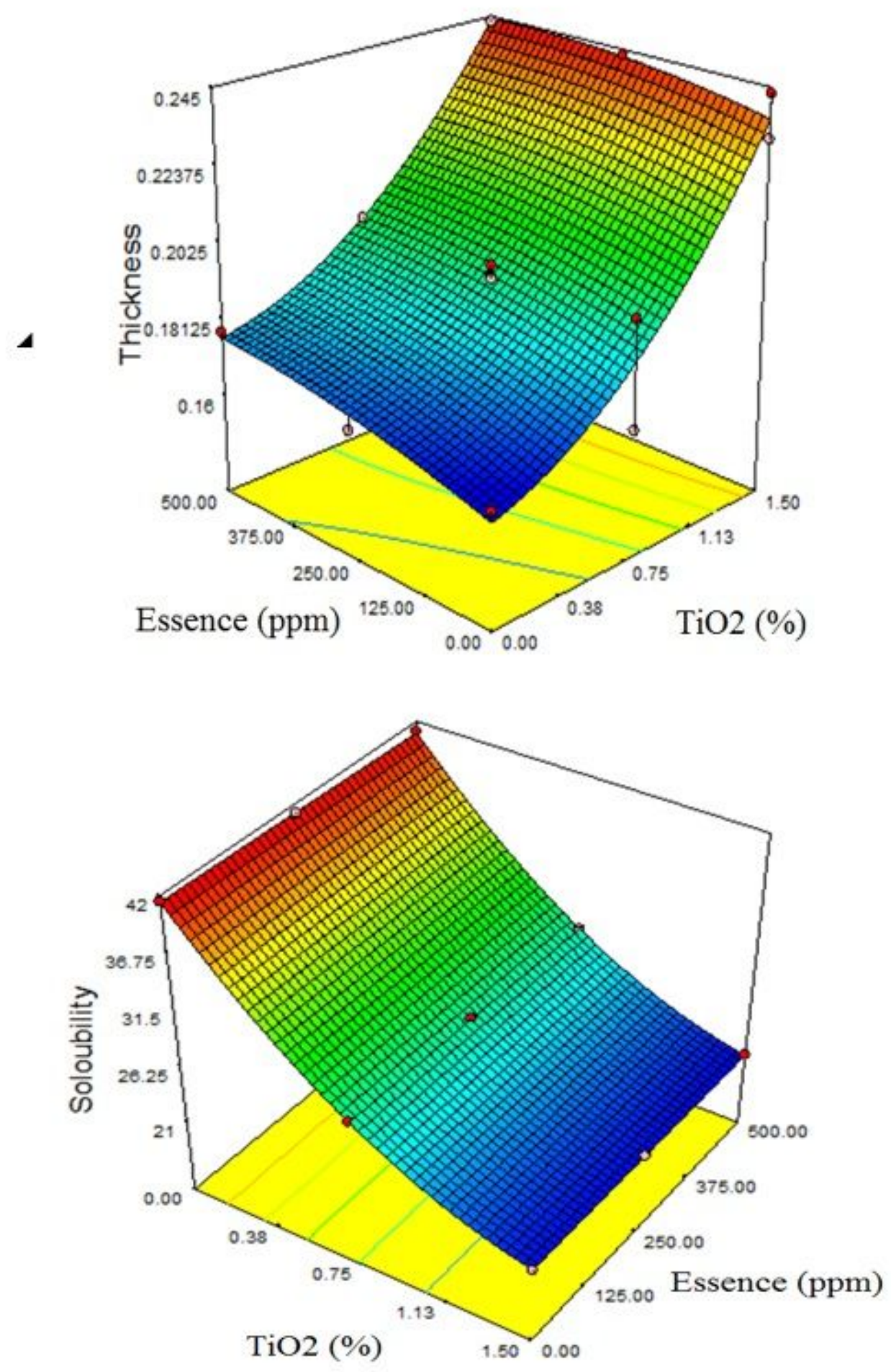

Figure 2

3D curves of the effect of $\mathrm{TiO} 2$ and essence on thickness and solubility 

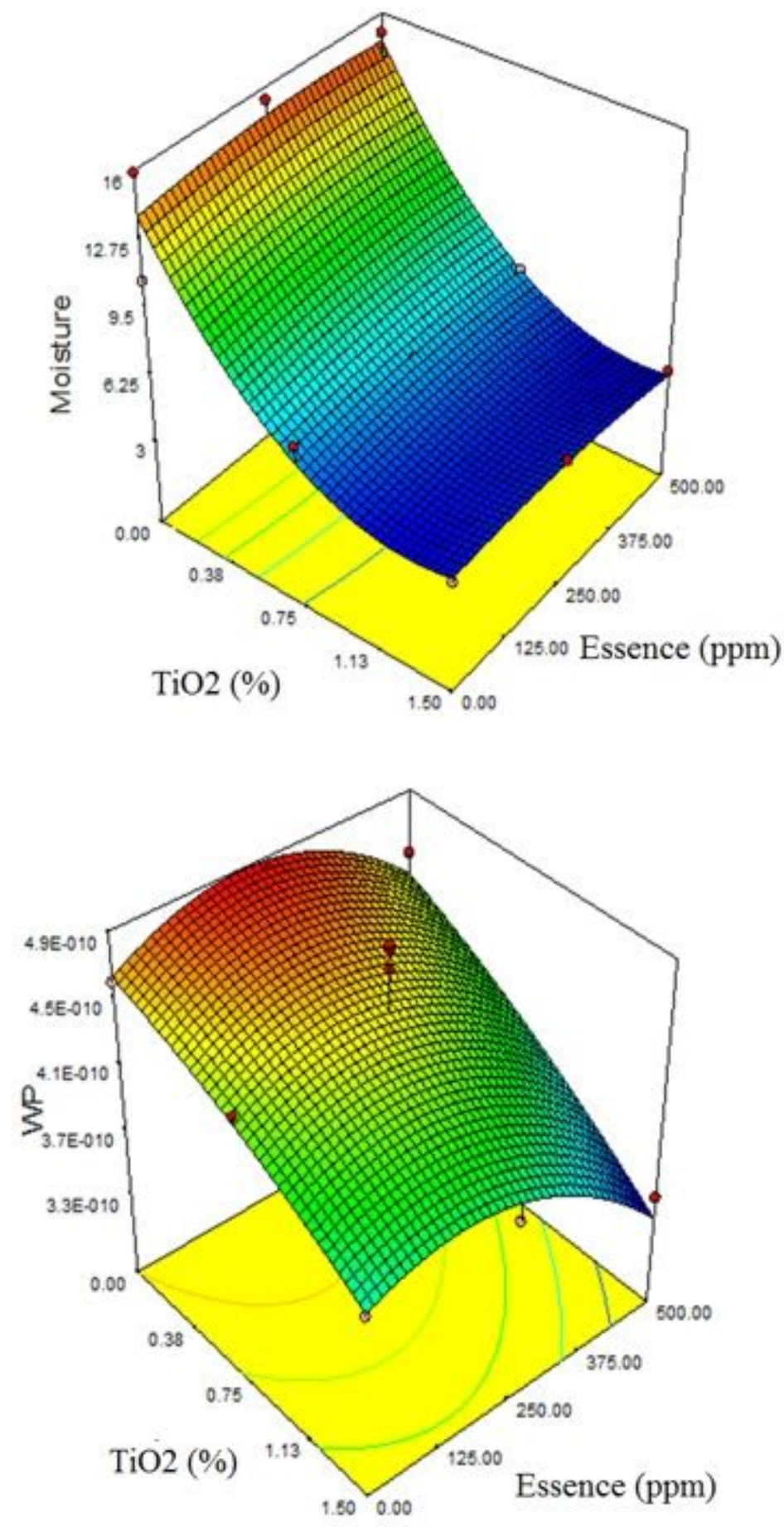

Figure 3

3D curves of the effect of TiO2 and essence on Moisture and WVP 

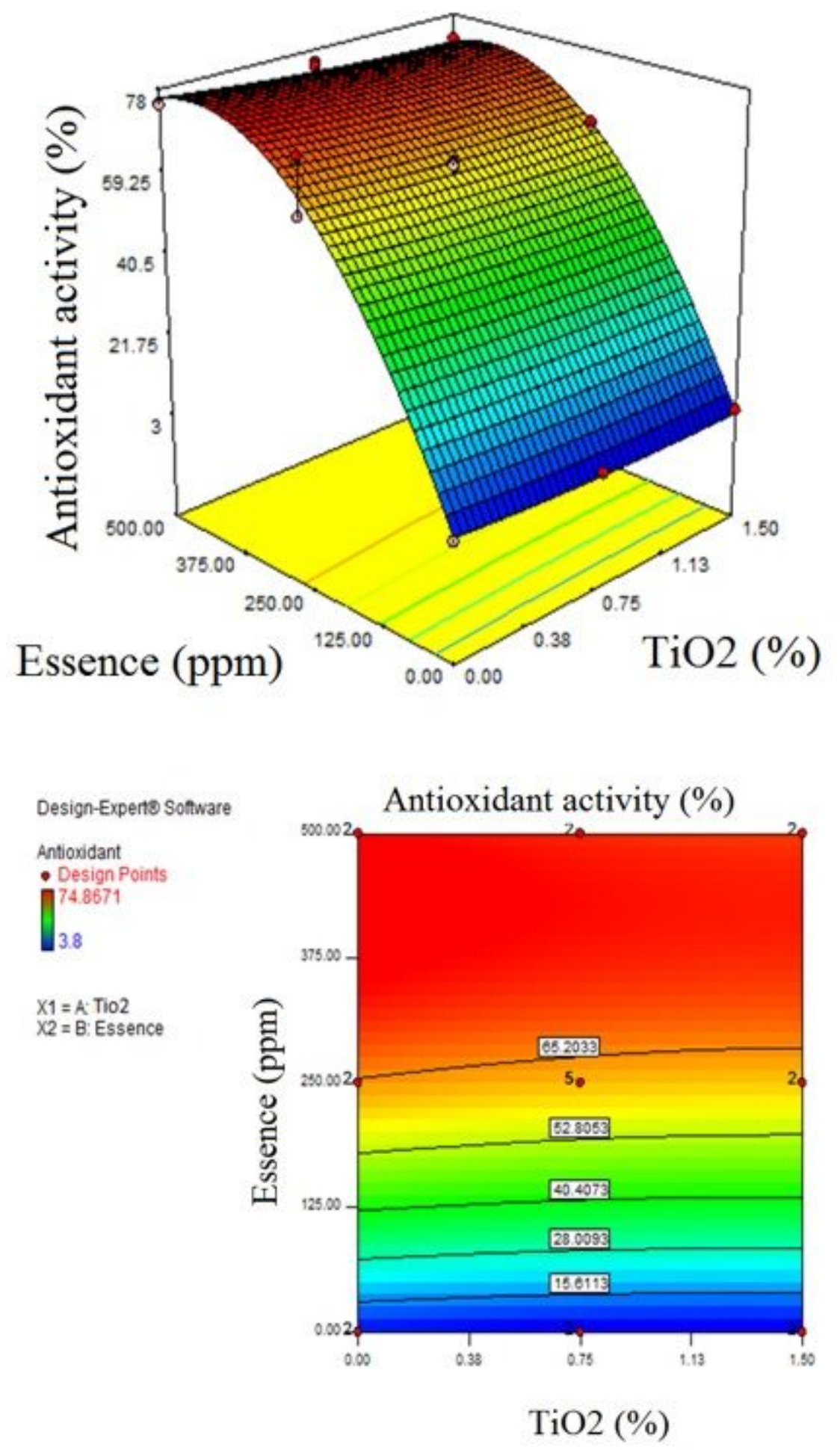

Figure 4

3D curve and contour plot of the effect of $\mathrm{TiO} 2$ and essence on antioxidant activity 

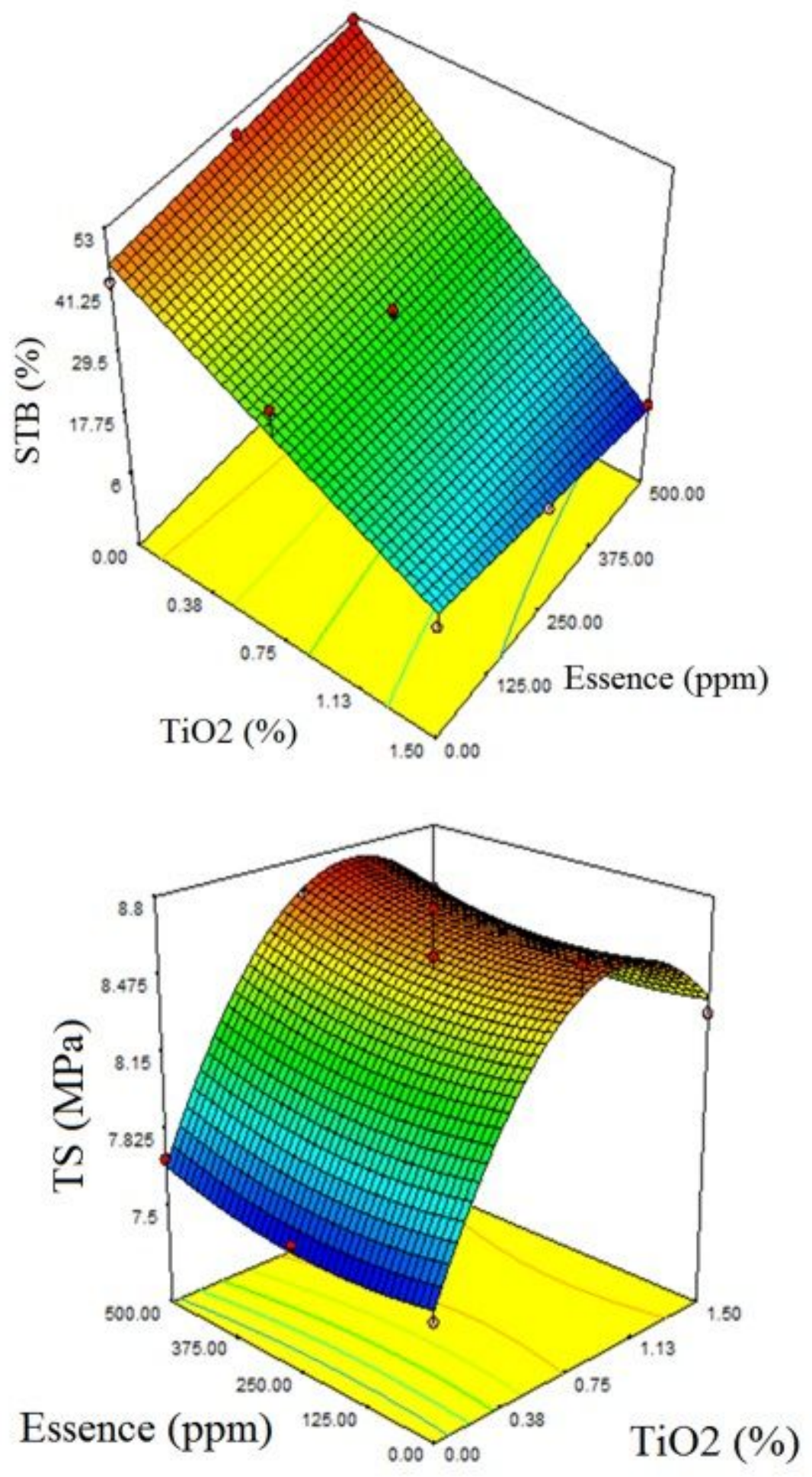

Figure 5

3D curve of the effect of TiO2 and essence on STB and TS 

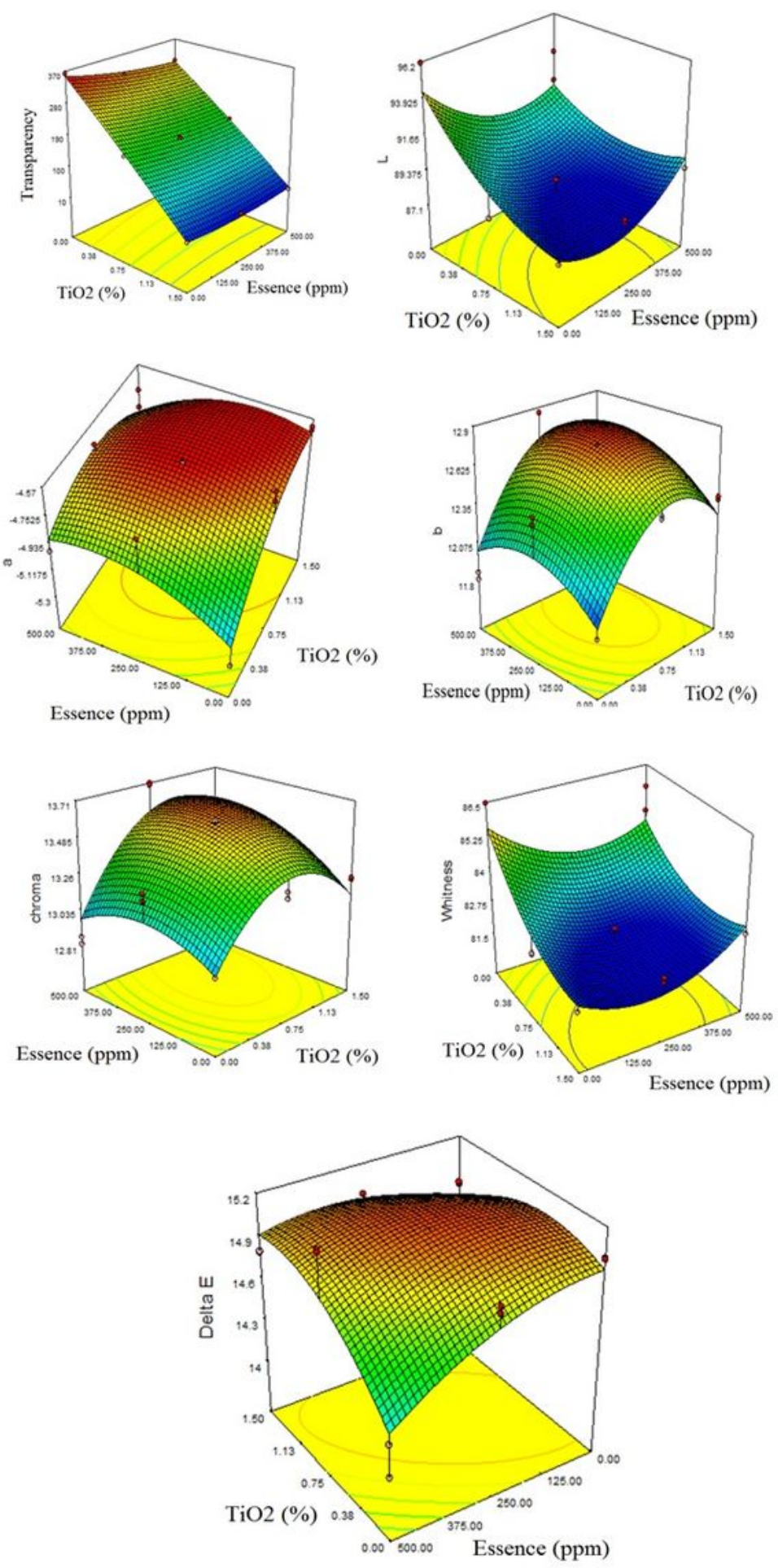

\section{Figure 6}

3D curve of the effect of $\mathrm{TiO} 2$ and essence on transparency and color properties 

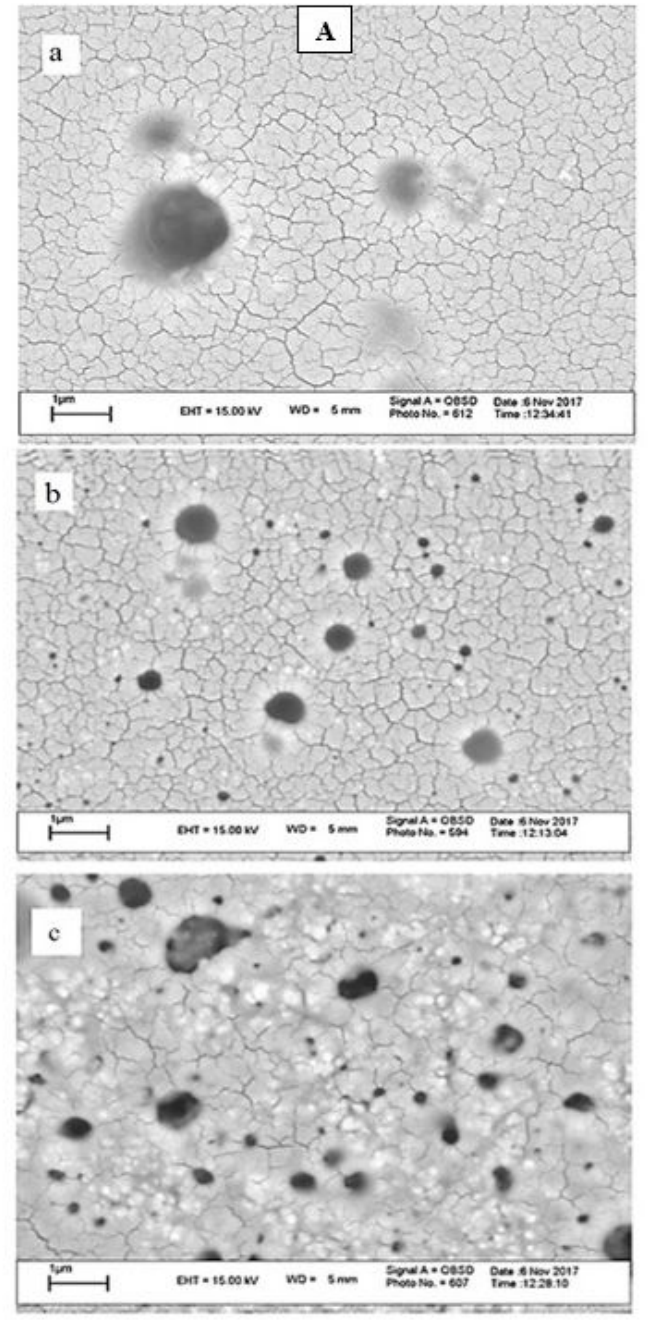

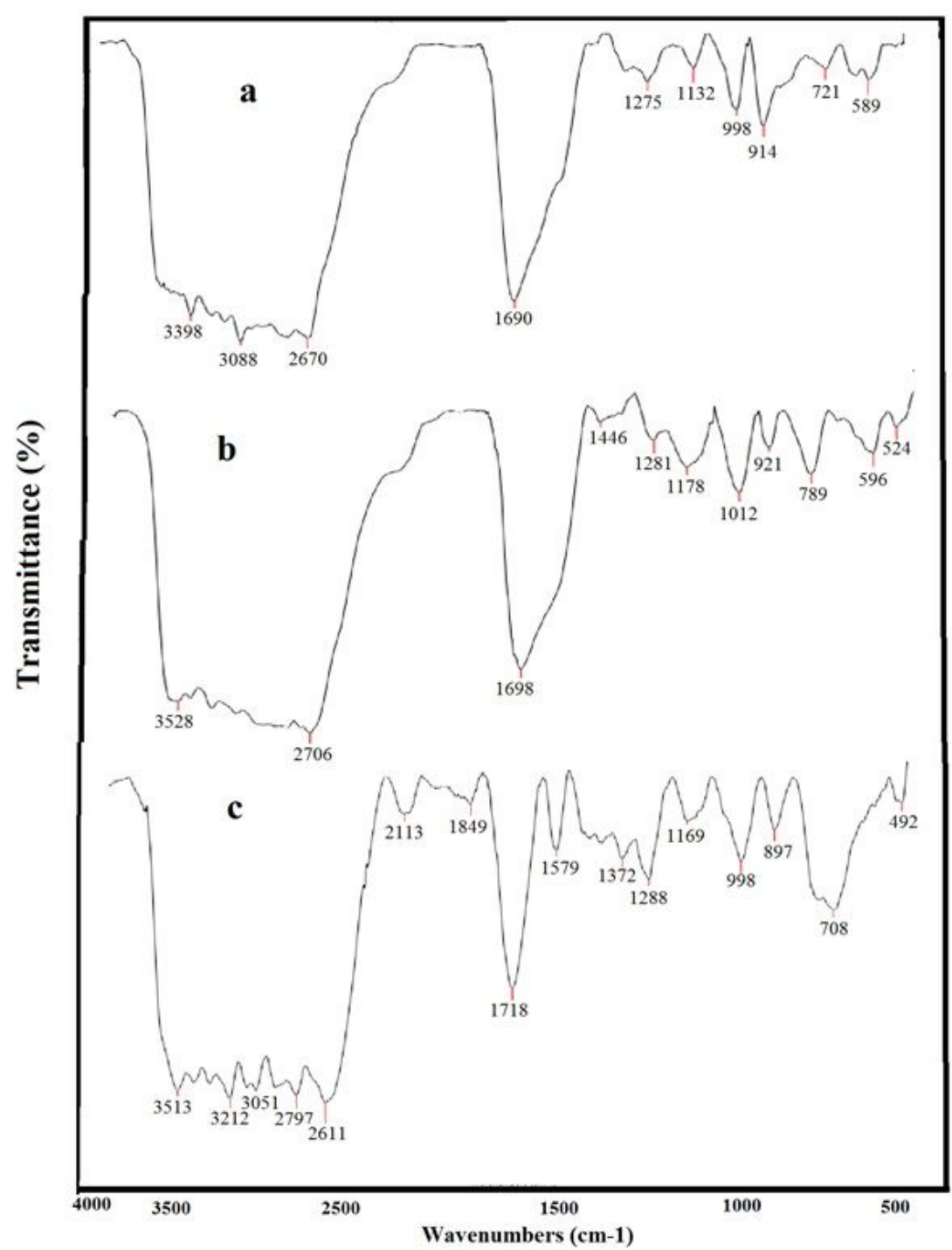

Figure 7

SEM images (A) and FTIR spectra (B) of sodium caseinate film (a), sodium caseinate/TiO2 0.75\%/essence 250 ppm (b) and sodium caseinate/TiO2 1.5\%/essence 500 ppm (c) 